\title{
Islet neogenesis associated protein transgenic mice are resistant to hyperglycemia induced by streptozotocin
}

\author{
David A Taylor-Fishwick ${ }^{1,2}$, Angela Bowman ${ }^{1}$, Natasha Hamblet ${ }^{1}$, Paul Bernard ${ }^{4}$, David M Harlan ${ }^{4}$ \\ and Aaron I Vinik ${ }^{1,3}$ \\ Departments of ${ }^{1}$ Internal Medicine, ${ }^{2}$ Microbiology and Molecular Cell Biology, ${ }^{3}$ Anatomy and Pathology, Eastern Virginia Medical School, 855 W Brambleton \\ Avenue, Norfolk, 23510 Virginia, USA \\ ${ }^{4}$ NIDDK, NIH, DHHS, Mark O Hatfield Clinical Research Center, Room 5-5940, Bethesda, Maryland 20892, USA \\ (Requests for offprints should be addressed to D A Taylor-Fishwick, Rm 215 Suite B, Eastern Virginia Medical School, Strelitz Diabetes Research Institute, \\ 855 W Brambleton Avenue, Norfolk, Virginia 23510, USA; Email: taylord@evms.edu)
}

\begin{abstract}
Islet neogenesis associated protein (INGAP) is a protein factor that can stimulate new islet mass from adult pancreatic progenitor cells. In models of islet neogenesis, INGAP expression is elevated in pancreatic acinar cells. Using a transgenic model to drive a sustained expression of INGAP in pancreatic acinar cells, we have identified a protection to chemical-induced hyperglycemia. A sustained expression of INGAP during development did not perturb islet development or basal blood glucose homeostasis, although $\beta$-cell mass and pancreatic insulin content were significantly increased in the INGAP transgenic mice. When challenged with a diabetogenic
\end{abstract}

dose of streptozotocin (STZ), mice carrying the INGAP transgene did not become hyperglycemic. In contrast, wild-type mice became and remained hyperglycemic, blood glucose $>$ $550 \mathrm{mg} / \mathrm{dl}$. The serum insulin levels and islet morphology were preserved in the transgenic mice after STZ treatment. These data suggest that the sustained expression of INGAP in the acinar pancreas confers resistance to a diabetogenic insult. The INGAP transgenic mouse provides a new model to uncover factors that are protective to diabetes onset and biomarkers to track $\beta$-cell pathology.

Journal of Endocrinology (2006) 190, 729-737

\section{Introduction}

A common pathology associated with diabetes onset is a loss of the functional pancreatic $\beta$-cell mass (Bell \& Polonsky 2001). The development of type 1 diabetes originates from an autoimmune-mediated destruction of $\beta$-cell mass (Mathis et al. 2001) and the onset of type 2 diabetes follows a progressive loss of $\beta$-cell mass (Butler et al. 2003), in which there is an approximately $50 \%$ reduction in $\beta$-cell mass upon diagnosis of type 2 diabetes (UKPDS Group 1995) and a steady annual decline thereafter. A central approach to treat diabetes, therefore, involves the replacement/replenishment of functional $\beta$-cell mass (Vinik et al. 2004a, 2004b). Strategies to restore $\beta$-cell mass include islet transplantation, proliferation of existing $\beta$ cells or re-deriving $\beta$ cells from embryonic or adult stem cells. The later method incorporates islet neogenesis, a process thought to involve inductive factors to promote new pancreatic islet mass from endogenous precursor cells (Vinik et al. 1997, Baggio \& Drucker 2002, Bonner-Weir et al. 2004, Paris et al. 2004, Vinik et al. 2004a, 2004b). Unlike strategies based upon transplantation that are limited by donor supply and immunosuppressant toxicity (Hirshberg et al. 2003), islet neogenesis relies on autologous precursor cells and therefore circumvents the complications associated with long-term immunosuppression.

Islet neogenesis associated protein (INGAP) was first identified in hamsters undergoing neogenesis (Rafaeloff $e t$ al. 1996, 1997, Vinik et al. 1997). Endogenous INGAP expression and islet neogenesis occur concurrently (Del Zotto et al. 2000). INGAP has a molecular weight of $16 \cdot 8 \mathrm{kDa}$ and is related to the type 2 C-lectins (Taylor-Fishwick et al. 2003, Vinik et al. 2004a, 2004b). The organization of INGAP's 175 amino acids classifies it as a member of the group 2 superfamily of reg-related proteins (Okamoto 1999). In addition to the biological efficacy of INGAP, a pentadecapeptide derived from the INGAP holoprotein retains biological activity (Rosenberg et al. 2004). INGAP or INGAP-peptide administered to rodents (Rosenberg et al. 1996, 2004) or dogs (G Pittenger \& D TaylorFishwick, unpublished observations) stimulates new islet growth as evidenced by elevated $\beta$-cell mass identified in quantitative histological and molecular analyses of insulin. Further, INGAP therapy reversed established hyperglycemia in rodent models of diabetes (Gold et al. 1998, Rosenberg et al. 2004). Additionally, in human clinical trials, INGAP peptide increased c-peptide secretion in subjects with type 1 diabetes and reduced $\mathrm{HbA} 1 \mathrm{c}$ levels in subjects with type 2 diabetes (Ratner \& Feeley 2005a,b). 
Moreover, INGAP peptide enhances $\beta$-cell-secretory responses (Borelli et al. 2005) and promotes duct to islet transdifferentiation in vitro (Jamal et al. 2005). During the process of islet neogenesis, inductive factors, such as INGAP, stimulate protodifferentiated cells residing in the pancreatic duct to differentiate, expand, and bud to initially form islet-like clusters (Rosenberg 1995, Baggio \& Drucker 2002, Bonner-Weir et al. 2004, Vinik et al. 2004a,b, Suarez-Pinzon et al. 2005). Last, INGAP secretion is upregulated in rodent models of injuryinduced neogenesis, such as the partial duct occlusion model in hamster (Rafaeloff et al. 1997), mouse duct ligation model, and the rat partial pancreatectomy model (Song et al. 2005). Upregulated INGAP expression during islet neogenesis predominates in the pancreatic acinar tissue (Rafaeloff et al. 1997, Vinik et al. 1997).

In this study, we have explored the anti-diabetogenic effect of a sustained pancreatic acinar tissue expression of INGAP by developing a transgene construct, in which INGAP is driven by the $-500 /+8$ rat elastase- 1 enhancer. Analysis of mice carrying this transgene has identified a unique phenotype that could facilitate the discovery of biomarkers for diabetes pathogenesis and resistance to $\beta$-cell damage.

\section{Materials and Methods}

\section{FVB/N mice}

All studies were performed with the approval of the Animal Care and Use Committee. Mice kept in a temperature and humidity-controlled room with a $12 \mathrm{~h}$ light: $12 \mathrm{~h}$ darkness cycle, were provided standard Harlan rodent diet (Harlan Teklad, Indianapolis, IN, USA) and water ad libitum. Mice were weaned at an age of 28 days. Genotyping of mice was performed on DNA extracted (Promega Wizard Genomic Purification kit; Promega) from a $1 \mathrm{~cm}$ tail clip. Mice studied were 3-4-months old. Blood glucose was measured at specified time points, using samples obtained in tail pricks, with a pre-calibrated Advantage Accu-Chek glucometer (Boehringer-Mannheim, Indianapolis, IN, USA). Blood, collected via cardiac bleed in gel separator tubes (BD, Franklin Lakes, NJ, USA), was spun at 2800 r.c.f. for $5 \mathrm{~min}$ with sera recovered being stored at $-80^{\circ} \mathrm{C}$. Blood insulin was measured by ELISA (ALPCO, Windham, NH, USA), as per the manufacturers instructions. For BrdU analysis, mice were injected with $100 \mathrm{mg} / \mathrm{kg}$ BrdU (Sigma) in saline and pancreata removed upon euthanasia $12 \mathrm{~h}$ later.

\section{Transgene construct and genotyping}

INGAP mRNA (region 19-766 of GenBank U41738) was cloned at a BamHI restriction site downstream of the rat elastase 1 enhancer that was kindly provided by Dr Galvin Swift (sequence 240-748 of GenBank L00112; Southwestern Medical Centre, University of Texas, Dallas, TX, USA) and a XhoI restriction site upstream of the rat insulin 1 poly-A tail (sequence 39262-40162 of GenBank AC098563). The resulting 2446 bp transgene was excised by restriction enzymes HindIII and ApaI. The transgenic mouse line termed elastage promoter-INGAP (EPINGAP) was generated through nuclear injection of the transgene as previously described (Harlan et al. 1994). To genotype the mice, genomic PCR was performed using primers to generate a $981 \mathrm{bp}$ product, which crossed the INGAP/poly-A junction (forward: 5'-TATTATTGAAGCTCACATGGACAAGG- $3^{\prime}$ and reverse: $5^{\prime}$-CACTGATCCACGATGCCGCGC- $3^{\prime}$ ) or primers to generate a 536 bp product, which crossed the elastase enhancer/INGAP junction (forward $5^{\prime}$-TGTGCTTTTCCCTGCCTTCTAC- $3^{\prime}$ and reverse $5^{\prime}$ ACTTCCATCCACTTCCGTTGG-3'). Detection of both PCR products confirmed incorporation of the complete transgene.

\section{STZ treatment in vivo}

Twenty-four hours before the initiation of treatment with streptozotocin (STZ), non-fasting blood glucose was measured using a pre-calibrated Advantage Accu-Chek glucometer (Boehringer-Mannheim) and mice were provided $10 \%$ sucrose water ad libitum. Mice were fasted for $16 \mathrm{~h}$, weighed, and given a single bolus i.p. injection of $140 \mathrm{mg} / \mathrm{kg}$ Zanosar (clinical grade STZ; Sicor Pharmaceuticals, Irvine, CA, USA) into the lower left abdominal quadrant. Two hours post-injection with STZ, food was replaced and 3 days postinjection, the $10 \%$ sucrose water was replaced with water. Non-fasting blood glucose levels and body weight were measured in the morning at days $3,5,8,10$, and 13 postinjection of Zanosar. Mice were defined hyperglycemic once the non-fasting blood glucose exceeded $275 \mathrm{mg} / \mathrm{dl}$. The study was terminated at day 14 , with blood and pancreata being harvested for analysis.

\section{Islet isolation}

Pancreata were minced and placed in Hanks balanced salt solution (HBSS)/Hepes buffer containing $0 \cdot 23 \mathrm{mg} / \mathrm{ml}$ liberase R1 (Roche Applied Science, Indianopolis, IN, USA) and $0.1 \mathrm{mg} / \mathrm{ml}$ DNase1 (Roche Applied Science), being digested for $30 \mathrm{~min}$ at $37^{\circ} \mathrm{C}$ in an agitating water bath. Upon termination with ice-cold HBSS containing $10 \%$ fetal bovine serum (FBS), the digested tissue was filtered through a $380 \mu \mathrm{m}$ mesh, washed and separated on an Optiprep gradient (AxisShield, Norton, MA, USA). Recovered islets were washed in PBS prior to RNA extraction in Trizol (Invitrogen). Primers used for INGAP PCR were $5^{\prime}$-TTTCCTGCCTGATTCC- $3^{\prime}$ and $5^{\prime}$-TCATACTTGCTTCCTTGTCC- $3^{\prime}$.

\section{In situ hybridization}

Expression plasmid for INGAP (pcDNA3-INGAP) was linearized with EcoRI (sense probe) or XhoI (antisense probe). The riboprobes were synthesized using T7/SP6 RNA polymerase and digoxigenin RNA-labeling mix (Roche 
Applied Science). INGAP riboprobes were precipitated in $\mathrm{LiCl} /$ ethanol and resuspended in TE buffer $(\mathrm{pH} 7 \cdot 5)$. Whole pancreas was cryopreserved in OCT (Ted Pella, Redding, CA, USA) and prepared for hybridization as previously described (Prado et al. 2004). Transcripts were detected using 1:5000 $\alpha$-digoxigenin IgG-Fab-alkaline phosphatase (Roche Applied Science) by incubating overnight at $4{ }^{\circ} \mathrm{C}$. Following washes in maleic acid buffer containing $0 \cdot 1 \%$ Tween-20, visualization was achieved with BM Purple precipitating solution (Roche Applied Science). Slides were sealed in Vectamount (Vector Labs, Burlingame, CA, USA) and images captured with DP-70 camera on an Olympus BX-51 microscope.

\section{Immunohistochemistry}

Pancreata were fixed in 10\% formalin (Fisher Chemicals, Fairlawn, NJ, USA) and embedded in paraffin. Tissue sections $(5-7 \mu \mathrm{m})$ were deparaffinized and rehydrated using xylene and ethanol dilutions. Sections were stained with $\mathrm{H} \& \mathrm{E}$, aldehyde fucin, trichrome and by antigen immunolocalization. Prior to immunodetection sections were blocked with Superblock buffer (Pierce, Rockford, IL, USA) for $30 \mathrm{~min}$. They were incubated for $4 \mathrm{~h}$ at room temperature with either 1:1000 mouse anti-glucagon (Sigma), $10 \mu \mathrm{g} / \mathrm{ml}$ mouse anti-Glut-2 (Alpha Diagnostic Labs, San Antonio, TX, USA), 1:1000 mouse anti-insulin (Sigma), 1:2000 Rabbit anti-INGAP or 1:2000 Rabbit Anti-Glucagon (Zymed Labs, San Francisco, CA, USA). Antibodies were diluted in blocking buffer. Following three PBS wash cycles, immunospecific signal was visualized by a 30-min incubation with either 1:1000 anti-mouse tetramethyl rhodamine iso-thiocyanate (TRITC) (Sigma), 1:1000 anti-rabbit FITC (Sigma) or species-specific peroxidase/alkaline phosphatase Vector ABC kits (Vector Labs) following the manufacturer's instructions. Fluorescent detection was counterstained with 1:100 000 DAPI (Sigma) and mounted using Fluoromount-G (Southern Biotechnology, Birmingham, AL, USA). Non-specific staining was excluded by substituting an irrelevant species-matched primary antibody. Images were recorded using a DP-70 camera with a BX-51 Microscope. Quantitation was analyzed using IMAGE PRO 5.0 (Media Cybernetics, Inc., Silver Spring, MD, USA). For BrdU detection, sections were incubated for $5 \mathrm{~min}$ in $2 \mathrm{~N} \mathrm{HCl}$ and washed in PBS prior to 2-h incubation with 1:20 mouse anti-BrdU (Becton-Dickinson, Dickinson Mountain View, CA, USA) in binding buffer (PBS containing $0 \cdot 2 \%$ Triton, $5 \%$ goat serum) followed by 30-min incubation with 1:1000 biotinylated goat anti-mouse-IgG (Sigma) in binding buffer. Antigen localization was visualized using streptavidin-HRP Vectastain Elite kit (Vector Labs) according to the manufacturer's directions. Terminal deoxynucleotidyl transferase-mediated deoxyuridine triphosphate (dUTP) nick end-labeling analysis was performed using the in situ Cell Death Detection Kit (Roche Applied Science) according to the manufacturer's recommendations. Prior to staining, sections were microwaved at $60 \%$ power for $5 \mathrm{~min}$ in $100 \mathrm{mM}$ sodium citrate $(\mathrm{pH} 6 \cdot 0)$.

\section{Quantitation of $\beta$-cell mass}

Transverse sections of whole pancreata were serial sectioned at $5 \mu \mathrm{m}$ intervals and mounted onto the slides. Randomly selected starting sections and then every tenth section $(\sim 50 \mu \mathrm{m}$ apart $)$ were selected for analysis. Sections were stained for insulin. Quantitation used established techniques (Bonner-Weir 2001, Rosenberg et al. 2004); briefly, the insulin-positive area falling into ten randomly chosen areas of a defined size, was determined and normalized to the unified area and weight of the pancreas. For each analysis greater than four sections from three mice of each line were analyzed.

\section{Pancreatic and serum insulin content}

Freshly extracted pancreas was weighed, homogenized, and extracted in a 20-fold volume of acid ethanol overnight at $4{ }^{\circ} \mathrm{C}$. Insulin content was determined by RIA (Linco Research, St Charles, MI, USA) and normalized to protein concentration determined by the Bradford assay. Serum insulin was measured by ELISA (ALPCO, Windham, $\mathrm{NH}$, USA) as per the manufacturers directions.

Results are shown as mean \pm S.E.M. Significance of the data was evaluated by non-paired Student's $t$-test. $P<0 \cdot 05$ was judged significant. Analyses were performed using Graphpad prism V4.0 software (Graphpad software, San Diego, CA, USA).

\section{Results}

Creation of EP-INGAP transgene and expression of INGAP in transgenic mice

For generation of the INGAP transgene, INGAP cDNA was inserted by directional restriction cloning between the rat elastase enhancer (Kruse et al. 1993) and the poly-A tail of the rat insulin gene, as shown in Fig. 1A. In order to direct the expression of INGAP more specifically into the acinar tissue, the region of the elastase enhancer used to drive INGAP was that defined as $-500 /+8$. Expression of the INGAP transgene in the pancreas was confirmed by RT-PCR, in situ hybridization, and immunohistochemistry (Fig. 1). INGAP mRNA was detected in the pancreas of the EP-INGAP transgenic line, but not wild-type mice (Fig. 1B). The expression of INGAP message was localized to the acinar tissue of the pancreas using in situ hybridization of an INGAP-riboprobe and no hybridization signal was detected in control pancreas sections (data not shown). Further, expression of INGAP was detected in the acinar region of the pancreas using an anti-peptide antibody to INGAP (peptide INGAP ${ }^{20-39}$ ). INGAP immunoreactivity in pancreatic acinar tissues was patchy in the EP-INGAP mouse (arrows, Fig. 1C), whereas no signal was observed in the wildtype mouse (Fig. 1D). Islets were isolated from EP-INGAP mice 


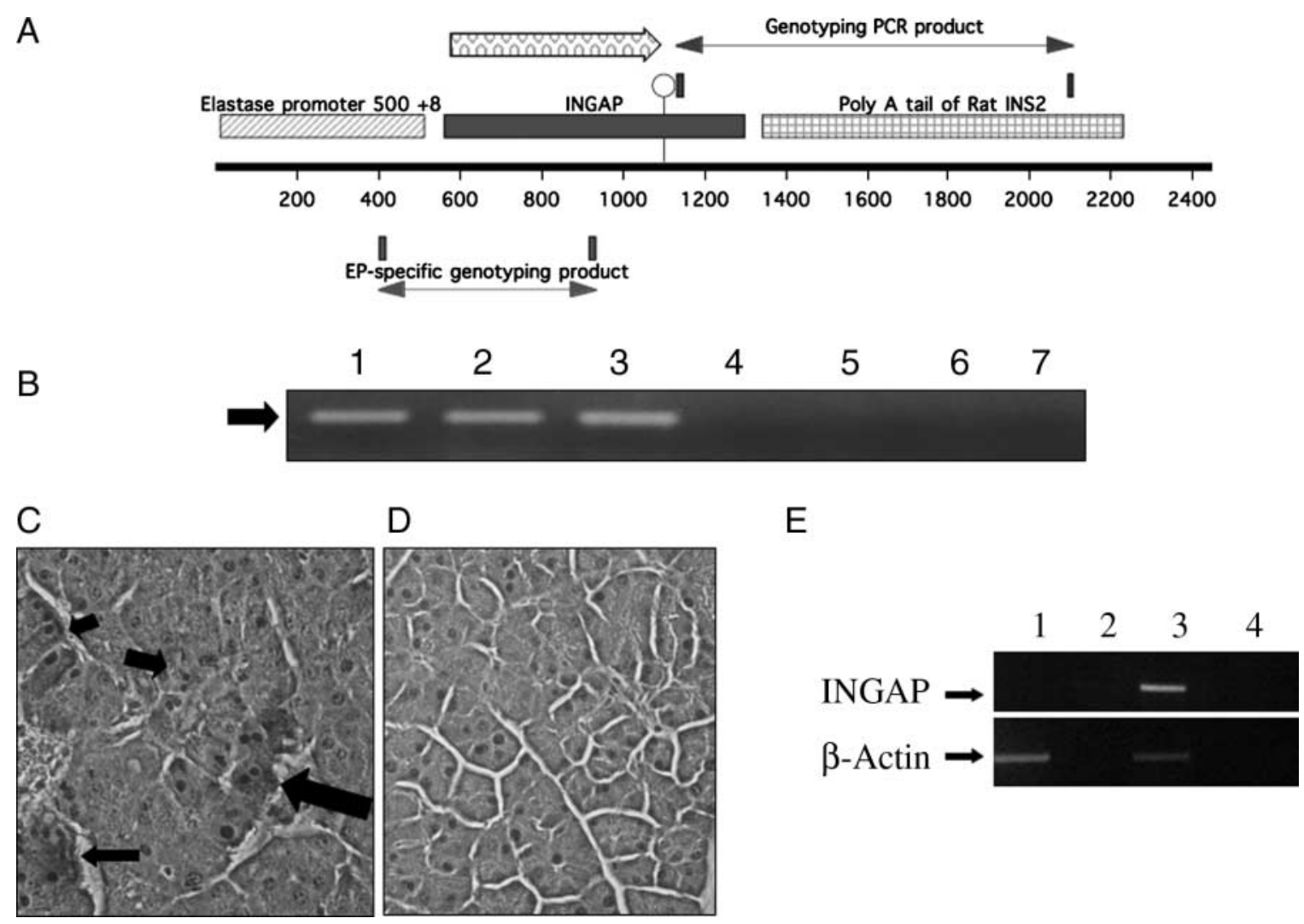

Figure 1 Expression of INGAP driven by the elastase enhancer. (A) Schematic of the EP-INGAP transgene shows the relative locations of the elastase enhancer, INGAP and insulin poly-A tail. The INGAP transcript is shown by an arrow as are the locations of primer pair and PCR products used to genotype the mice. (B) RT-PCR analysis for INGAP expression of pancreata from three EP-INGAP mice (lanes 1-3) and three wild-type mice (lanes 4-6). The position of the $450 \mathrm{bp} \mathrm{INGAP} \mathrm{product} \mathrm{is} \mathrm{marked} \mathrm{with} \mathrm{an} \mathrm{arrow.} \mathrm{Control} \mathrm{reaction}$ with no DNA template is shown (lane 7). INGAP expression in $5 \mu \mathrm{m}$ paraffin pancreatic sections from (C) EP-INGAP mice or (D) wildtype mice were stained with antibody to INGAP ${ }^{20-39}$ and developed with streptavidin HRP. Images shown are bright field phase contrast at a $40 \times$ objective and counterstained with hematoxylin. (E) PCR for INGAP and $\beta$-actin in isolated islets (lane 1) or whole pancreas (lane 3) from EP-INGAP mice are shown. Control reactions with no DNA template are shown (lanes 2 and 4).

and analyzed for expression of the INGAP transgene. No endocrine expression of transgenic INGAP was observed by PCR (Fig. 1E, lane 1) compared with whole pancreas (Fig. 1E, lane 3). The housekeeping gene product actin was detected in both isolated islets and whole pancreas (Fig. 1E, lanes 1 and 3). Tissues from EP-INGAP mice and wild-type mice were screened for the expression of INGAP message by Northern blot analysis. No INGAP signal was detected in wild-type mice, and INGAP message in the EP-INGAP mice was restricted to the pancreas and not detected in stomach, spleen, duodenum, liver, kidney, lung, skeletal muscle, brain, heart, or bone marrow (data not shown). Since endogenous elastase is also detected in the stomach (Kruse et al. 1993), this expression pattern supports a restricted expression of INGAP driven by the elastase enhancer.

\section{Basal characteristics of EP-INGAP mice}

The EP-INGAP mouse line was compared with the wildtype (non-transgenic littermate) mouse line. Both mouse lines were euglycemic (average blood glucose $128 \pm 27$ and $128 \pm$ $25 \mathrm{mg} / \mathrm{dl}$ for wild type and EP-INGAP respectively) and gained equivalent age-related weight and pancreas weight (pancreatic weight expressed as a percentage of total body weight at 12 weeks was $0 \cdot 758 \pm 0 \cdot 11 \%$ and $0 \cdot 764 \pm 0 \cdot 09 \%$ for wild type and EP-INGAP respectively). Additionally, there was no statistical difference in the response of the mouse lines to an i.p. glucose tolerance test. Both lines $(n=6$ per line) showed equivalent time-dependent increase and normalization in blood glucose concentrations following an i.p. injection of $2 \mathrm{~g} / \mathrm{kg}$ dextrose (Fig. 2A).

The architecture of the islet in the EP-INGAP mice was compared with non-transgenic littermate controls by immunohistochemistry. Using $5 \mu \mathrm{m}$ paraffin sections, pancreas tissues were stained with $\mathrm{H} \& \mathrm{E}$, aldehyde fucin (data not shown) and hormone-specific immunocytochemistry (Fig. 2B). No changes in pancreatic organization were detected. Moreover, the cellular topology of insulin-positive cells (arrows, Fig. 2B) and glucagon-positive cells (arrows, Fig. 2B) was analogous between the mouse lines. Quantitative 
A

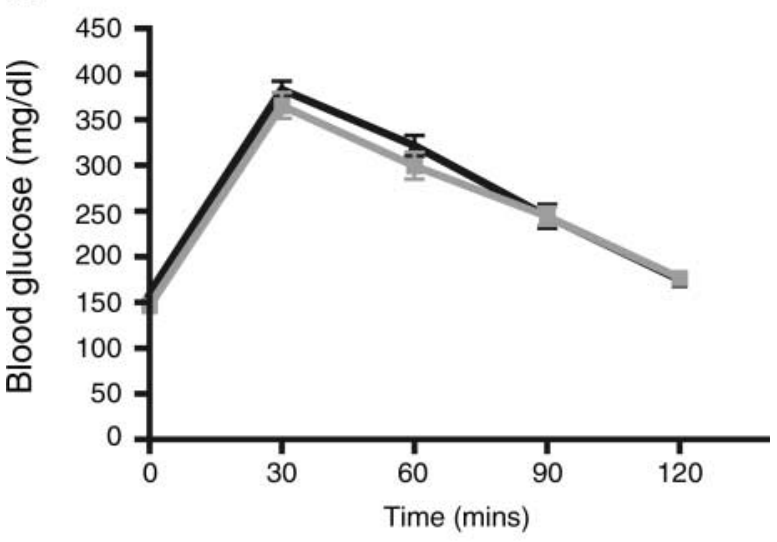

B
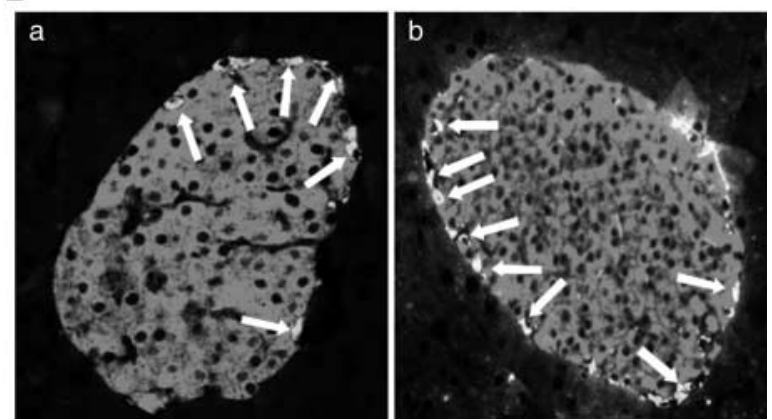

Figure 2 (A) IPGTT in EP-INGAP and wild-type mice. Mice ( $n \geq 5$ /group) were dosed with $2 \mathrm{~g} / \mathrm{kg}$ D-glucose and blood glucose measured over time in EP-INGAP (triangle) and wild-type (square) mice. (B) EP-INGAP mice maintain islet architecture. Hormonespecific immunofluorochemistry is shown for insulin (arrows) and glucagon (arrows) in representative islets from (a) EP-INGAP mice and (b) wild-type mice.

analysis for total pancreatic islet mass and insulin content was performed (Fig. 3). The EP-INGAP mice had a significant $(P<0 \cdot 05)$ increase in both $\beta$-cell mass (insulin positive cells; $2 \cdot 1 \pm 0 \cdot 9$-fold) $2 \cdot 1 \pm 0 \cdot 9$-fold and in the total pancreatic insulin/protein ratio, $2 \pm 0 \cdot 8$-fold $(2 \pm 0 \cdot 8$-fold $)$ when compared with the wild-type line. Morphometric analysis of $\beta$ cell and islet size was studied (Fig. 4). No significant difference in individual $\beta$-cell area was observed between EP-INGAP and wild-type islets (data not shown). EP- INGAP mice had more small islets than wild-type mice shown in representative low power micrographs (Fig. 4A and $\mathrm{B}$ ) and histogram ranking the number of islets of defined size (Fig. 4C).

\section{Resistance to STZ-induced insulinemia}

To explore the functional differences between the strains, mice were challenged using the diabetogenic agent STZ. In wild-type $\mathrm{FVB} / \mathrm{N}$ mice given a single i.p. STZ injection of $140 \mathrm{mg} / \mathrm{kg}$, non-fasting blood glucose levels rose to $\geq 350 \mathrm{mg} / \mathrm{dl}$ and progressed to severe hyperglycemia (non-fasting blood glucose $\geq 550 \mathrm{mg} / \mathrm{dl}$ ) by day 5 postinjection; Fig. 5). The hyperglycemia was sustained for the rest of the 14-day study. All the mice in the wild-type group $(n=6)$ became hyperglycemic. In marked contrast, EP-INGAP mice did not become hyperglycemic at any point measured during the study following STZ administration.

STZ-treated mice were further analyzed by collecting blood samples at the end of the study for insulin (Fig. 6). Consistent with the reported mechanism of action for STZinduced hyperglycemia (Wilson et al. 1988), circulating insulin levels in the STZ-dosed wild-type mice were significantly $(P<0 \cdot 001)$ reduced being just $5 \%$ of that detected in non-STZ-treated mice. In contrast, EP-INGAP mice, which did not become hyperglycemic following STZ, had circulating insulin levels, which were comparable to the insulin levels detected in non-STZ-treated EP-INGAP and wild-type mice. Taken together, these data suggest that STZ at $140 \mathrm{mg} / \mathrm{kg}$ destroys pancreatic $\beta$ cells in wild-type $\mathrm{FVB} / \mathrm{N}$ mice such that the islets fail to produce insulin. However, administration of STZ at $140 \mathrm{mg} / \mathrm{kg}$ to EP-INGAP transgenic mice did not result in marked $\beta$-cell destruction, hyperglycemia, or decreased insulin levels. We also performed immunohistochemical analysis of mouse pancreata following STZ. Pancreas sections from STZ-treated wild-type FVB/N mice compared with non-STZ-treated controls revealed a reduction of $87 \% \pm 4 \quad(n=5)$ of the intraislet insulin immunoreactive $\beta$ cells (Fig. 7A, C and E top). Whereas a comparison between STZ-treated and non-STZ-treated EP-INGAP transgenic mice revealed an overall preservation of islet structure with $91 \% \pm 5(n=5)$ of the immunoreactive islet $\beta$-cell mass being preserved (Fig. 7B, D, and E, bottom).

\section{Discussion}

Previous studies have provided support for the hypothesis that INGAP is an important factor in an islet neogenesis cascade (Rafaeloff et al. 1997, Del Zotto et al. 2000, Gagliardino et al. 2003, Rosenberg et al. 2004, Vinik et al. 2004a,b). Despite these observations, the mechanisms by which INGAP acts on pancreatic cells to stimulate new islet growth is unclear. As INGAP expression is upregulated in the acinar pancreas during islet neogenesis, we have investigated the consequences of a sustained acinar tissue INGAP expression in terms of pancreas development, physiology, and diabetes susceptibility in transgenic mice with INGAP expressed under the control of the elastase-1 enhancer. INGAP expression was acinar pancreas-specific albeit with an irregular pattern of expression (Fig. 1). The elastase-1 promoter used in the EP-INGAP transgene was the $-500 /+8$ enhancer, which includes a repression element (located -500 to $-206 \mathrm{nt}$ ) that acts to suppress gene expression in $\beta$ cells driven by the $\mathrm{B}$ element in the shorter $-205 /+8$ enhancer sequence (Swift et al. 1989, MacDonald \& Swift 1998). This enhancer sequence has been described as producing a patchy expression (Zhu et al. 2004), when 
A

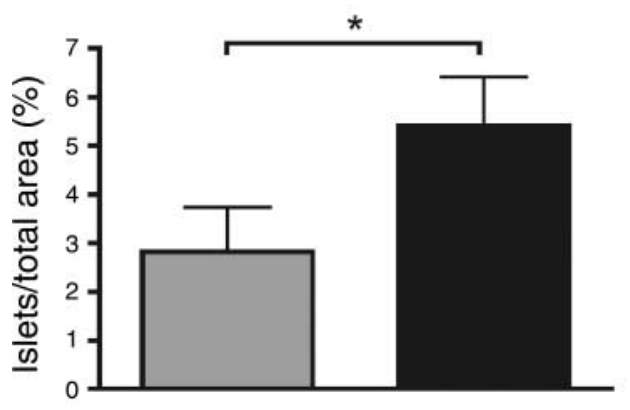

B

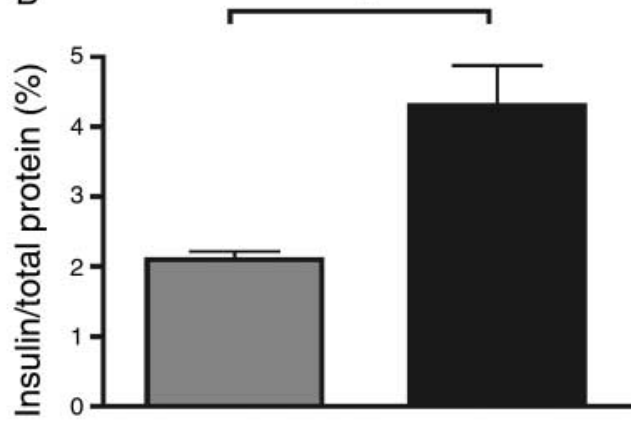

Figure 3 Increased $\beta$-cell mass in EP-INGAP mice. (A) $\beta$-cell quantitation and (B) determination of insulin/total protein ratio reveal a significant elevation in overall $\beta$-cell mass and pancreatic insulin content of EP-INGAP mice. ${ }^{*} P<0.05$.

compared with the truncated enhancer termed $-205 /+8$, and is consistent with the INGAP expression observed in the EP-INGAP mouse. Furthermore, the EP-INGAP transgene incorporates the INGAP secretion signal, thus INGAP should be secreted from cells as seen in established in vitro models (data not shown). Sustained INGAP expression did not disrupt pancreas development, rather an enhancement in $\beta$-cell mass was evident in terms of elevations in both islet mass and total pancreatic insulin content. This increase in $\beta$ cell mass was associated with an increase in the number of smaller islets rather than the creation of large super islets. Additionally, no significant change in proliferation/apoptotic

A

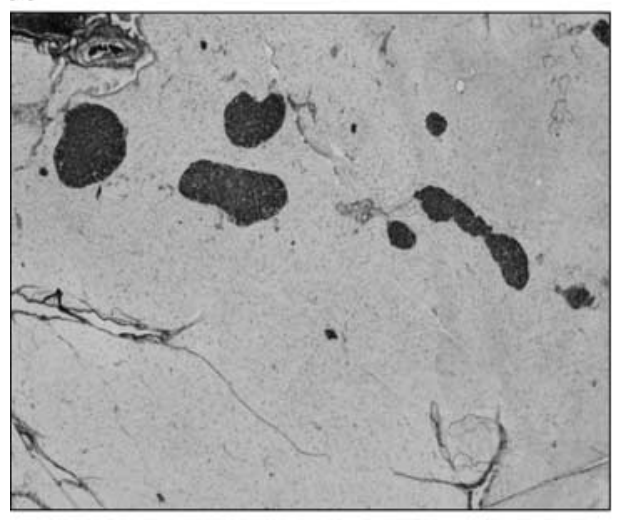

B
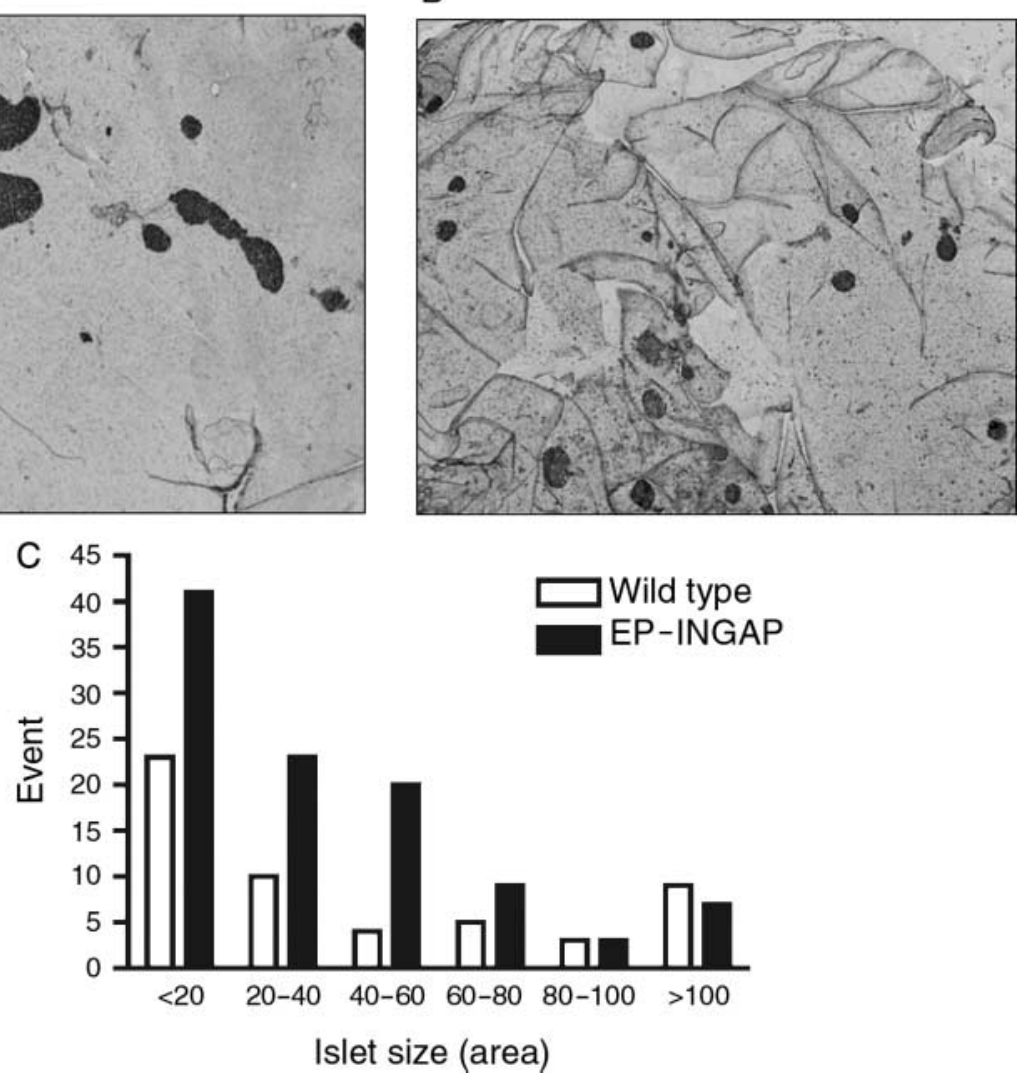

Figure 4 Low power $(4 \times$ objective) bright field micrographs of $(A)$ wild-type and (B) EP-INGAP pancreas stained with trichrome. (C) Quantitation of islet size. Graph shows number of islets defined by area ranges (arbitrary morphometric units) for equal randomly selected fields ( $n \geq 7$ ) for wild-type (open) and EP-INGAP (filled) mice. 


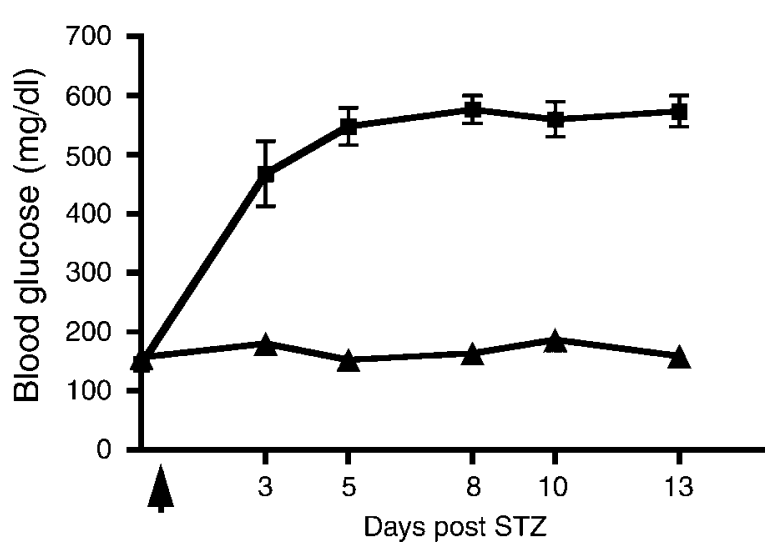

Figure 5 Resistance to streptozotocin-induced hyperglycemia in EP-INGAP mice. Wild-type mice (squares) and EP-INGAP mice (triangles) were dosed intraperitoneally with $140 \mathrm{mg} / \mathrm{kg} \mathrm{STZ} \mathrm{(arrow)}$ and blood glucose monitored. Data show mean blood glucose \pm S.E.M. for each group containing $\geq 5$ mice.

ratios of $\beta$ cells or ducts (not shown) were detected. Thus, these results suggest that the increase in islet mass may arise from a different pancreas modeling program (Slack 1995) in the EP-INGAP mice. These changes are being characterized in ongoing studies of the developing pancreas.

EP-INGAP transgenic mice were resistant to STZ-induced hyperglycemia and $\beta$-cell damage when treated with up to $140 \mathrm{mg} / \mathrm{kg} \mathrm{STZ}$. At a lower dose of STZ $(120 \mathrm{mg} / \mathrm{kg})$, the EP-INGAP mice remained euglycemic, whereas

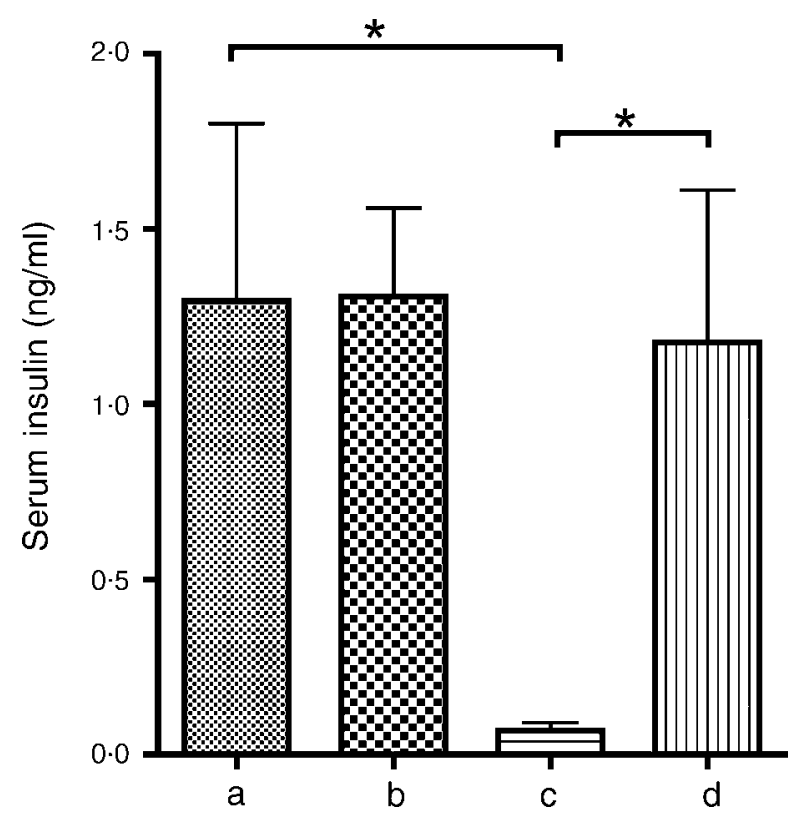

Figure 6 Serum insulin in normal and STZ-treated mice. Serum insulin from untreated mice (a and b) was compared with serum insulin obtained from age-matched mice 14 days after treatment with $140 \mathrm{mg} / \mathrm{kg} \mathrm{STZ} \mathrm{(c} \mathrm{and} \mathrm{d)} \mathrm{in} \mathrm{wild-type} \mathrm{mice} \mathrm{(} \mathrm{a}$ and c) and EP-INGAP mice ( $b$ and d). Shown are means \pm s.E.M. for mice with a minimum of five per group $\left({ }^{*} P<0 \cdot 001\right)$. approximately half the wild-type mice became hyperglycemic. Further, administration of STZ at $160 \mathrm{mg} / \mathrm{kg}$ and above resulted in toxicity and morbidity that was not related to $\beta$-cell destruction (data not shown). Possible mechanisms for the protection to STZ-induced hyperglycemia in EP-INGAP mice include: (a) reduction in STZ bio-distribution, (b) active islet neogenesis, or (c) resistance to STZ. STZ is a DNAalkylating agent (Yamamoto et al. 1981) that preferentially enters pancreatic $\beta$ cells through the glucose transporter 2 (GLUT2) transporter due to a glucose-like moiety within its chemical structure (Wilson et al. 1988). Using immunohistochemical staining and semi-quantitative RT-PCR analysis, we found no difference in the GLUT2 transporter expression between EP-INGAP and wild-type mice (data not shown). While the remote possibility that the GLUT2 transporter in the EP-INGAP line has a reduced affinity for STZ has not been excluded, there is no evidence to support a decrease in GLUT2 expression as the mechanism underlining STZ resistance in the EP-INGAP line. An alternative protective mechanism invokes islet neogenesis, which is a phenomenon that is associated with INGAP expression (Rafaeloff et al. 1997, Del Zotto et al. 2000, Rosenberg et al. 2004, Vinik et al. 2004a,b). Therefore, the possibility exists that, in the EP-INGAP line, the short-acting toxic actions of STZ are offset by the generation of new islet mass. This mechanism is unlikely to apply to this mouse model, since the first evidence of new islet mass in response to exogenous INGAP occurs approximately 10 days following INGAP administration (Rosenberg et al. 2004). Further, the predicted initial rise in blood glucose associated with STZinduced $\beta$-cell damage was not observed in EP-INGAP mice. Moreover, it is unlikely that smaller islets are more resistant to STZ, since a selective destruction of larger islets was not observed in EP-INGAP mice following STZ treatment. It would, therefore, appear that EP-INGAP mice have an intrinsic resistance to STZ-induced $\beta$-cell damage. This may reflect protection arising from the increase in $\beta$-cell reserve in EP-INGAP mice although alterations in other cellular pathways that confer protection cannot be eliminated. Evidence for a direct dose-dependent relationship between $\beta$-cell mass and STZ susceptibility has not been established (Kurup \& Bhonde 2000) and a proportional loss in $\beta$-cells was not observed in the islets from EP-INGAP mice treated with STZ. Moreover, the analysis of pancreatic protein expression by surface enhanced laser description/ionization time of flight mass spectrometry (SELDI-TOF-MS) identified significant differences between the EP-INGAP mice and wild-type mice. The peak-profiles defining these spectra were sufficient to separate the two mouse lines in a principal component analysis (D Taylor-Fishwick, G Malik and O Semmes, unpublished observations). Taken together, these data suggest that a sustained expression of INGAP in the EP-INGAP transgenic mice results in an altered physiological state that provides increased protection against $\beta$-cell damage when mice are challenged with a $\beta$-cell toxin. This new basal state in EP-INGAP mice correlates with a differential expression in pancreatic proteins that may underlay the cellular mechanism(s) conferring $\beta$-cell 

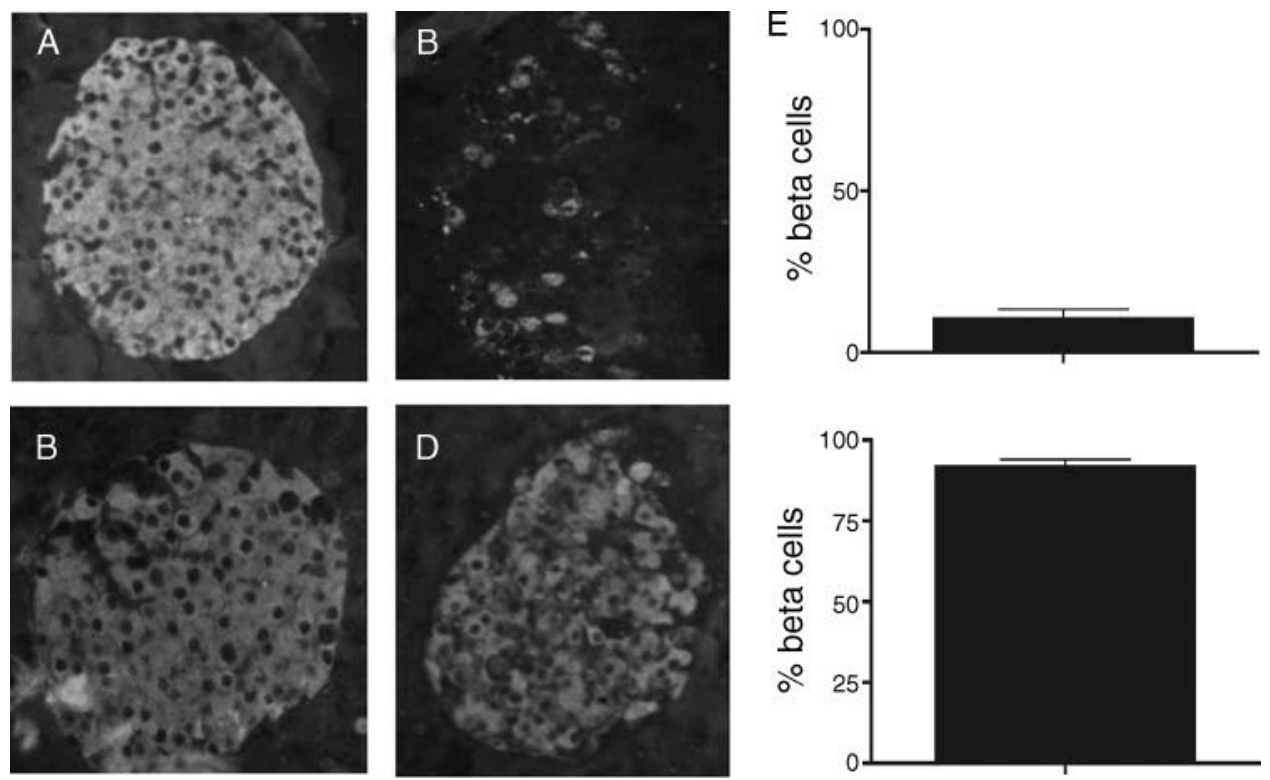

Figure 7 Reduced islet $\beta$-cell mass in STZ-treated wild-type mice. Shown are $5 \mu \mathrm{m}$ pancreas sections from wild-type (A and C) and EP-INGAP mice (B and D) either untreated (A and B) or 14 days after treatment with $140 \mathrm{mg} / \mathrm{kg}$ STZ (C and D). Islets were detected with indirect immunofluorescent staining for insulin. (E) Percent of islet area showing immunoreactivity to insulin after treatment with STZ in wild-type (top) and EP-INGAP (bottom) mice. Data show mean \pm S.E.M. $\%(n=5)$.

protection. Resistance to STZ-induced hyperglycemia has been reported in mice deficient in pancreatic insulin-like growth factor-I (Lu et al. 2004), in mice lacking the phosphatase and tensin homolog deleted on chromosome ten (PTEN) in adipose tissue (Kurlawalla-Martinez et al. 2005) and in mice that are deficient for poly (ADP-ribose) polymerase (Burkart et al. 1999). Whether INGAP plays a direct role in these pathways is unknown. INGAP has been reported to activate protein kinase B (AKT) phosphorylation (Jamal et al. 2005) and constitutive AKT activation results in an increased pancreatic $\beta$-cell mass and protection to STZ-induced diabetes (Bernal-Mizrachi et al. 2001, Tuttle et al. 2001). In the adipose tissue, AKTactivation is a hallmark of PTEN loss (Kurlawalla-Martinez et al. 2005). While indirect actions of INGAP expression may also be relevant, the generation of biomarkers for pathways conferring protection to $\beta$-cell damage would have utility in identifying individuals that are disease susceptible amongst pre-diabetics in addition to monitoring the efficacy of therapeutic regimens in established diabetes. A complete characterization of these candidate protein biomarkers and the cellular mechanisms associated with INGAP efficacy are ongoing researches.

This study is the first report of efficacy for full-length INGAP in the mouse. The sustained expression of INGAP in pancreatic acinar tissue resulted in increased $\beta$-cell mass and resistance to STZ-induced diabetes. While these two observations may not be causally linked, this exciting and novel animal model could provide a gateway to identify neogenesis-related pathways and new molecules to target in diabetes prevention and/or treatment.

\section{Acknowledgements}

We thank Dr Jeffrey Kupp, NIDDK/NIH, MD for generating the mouse lines, Dr Galvin Swift, Southwestern Medical Center, TX for generously providing the elastase enhancer, Drs G Malik and O J Semmes, EVMS, VA for the proteomic analysis and Dr T Jacot for islet isolation and PCR. This work was supported through research grants from the Diabetes Institutes Foundation, Cosmopolitan International and GMP Companies, Inc. The authors declare that there is no conflict of interest that would prejudice the impartiality of this scientific work.

\section{References}

Baggio LL \& Drucker DJ 2002 Harnessing the therapeutic potential of glucagonlike peptide-1: a critical review. Treatments in Endocrinology 1 117-125.

Bell GI \& Polonsky KS 2001 Diabetes mellitus and genetically programmed defects in beta-cell function. Nature $\mathbf{4 1 4}$ 788-791.

Bernal-Mizrachi E, Wen W, Stahlhut S, Welling CM \& Permutt MA 2001 Islet beta cell expression of constitutively active Akt1/PKB alpha induces striking hypertrophy, hyperplasia, and hyperinsulinemia. Journal of Clinical Investigation 108 1631-1638.

Bonner-Weir S 2001 Beta-cell turnover: its assessment and implications. Diabetes 50 S20-S24.

Bonner-Weir S, Toschi E, Inada A, Reitz P, Fonseca SY, Aye T \& Sharma A 2004 The pancreatic ductal epithelium serves as a potential pool of progenitor cells. Pediatric Diabetes 5 (Suppl 2) 16-22.

Borelli MI, Stoppiglia LF, Rezende LF, Flores LE, Del Zotto H, Boschero AC \& Gagliardino JJ 2005 INGAP-related pentadecapeptide: its modulatory effect upon insulin secretion. Regulatory Peptides 131 97-102. 
Burkart V, Wang ZQ, Radons J, Heller B, Herceg Z, Stingl L, Wagner EF \& Kolb H 1999 Mice lacking the poly(ADP-ribose) polymerase gene are resistant to pancreatic beta-cell destruction and diabetes development induced by streptozocin. Nature Medicine 5 314-319.

Butler AE, Janson J, Bonner-Weir S, Ritzel R, Rizza RA \& Butler PC 2003 Beta-cell deficit and increased beta-cell apoptosis in humans with type 2 diabetes. Diabetes 52 102-110.

Del Zotto H, Massa L, Rafaeloff R, Pittenger GL, Vinik A, Gold G, Reifel-Miller A \& Gagliardino JJ 2000 Possible relationship between changes in islet neogenesis and islet neogenesis-associated protein-positive cell mass induced by sucrose administration to normal hamsters. Journal of Endocrinology 165 725-733.

Gagliardino JJ, Del Zotto H, Massa L, Flores LE \& Borelli MI 2003 Pancreatic duodenal homeobox-1 and islet neogenesis-associated protein: a possible combined marker of activateable pancreatic cell precursors. Journal of Endocrinology 177 249-259.

Gold G, Broderick C, Caragna M, Williams G, Pittenger GL, Rafaeloff R, Reifel-Miller A, Borts T, Hale J, Churgay L et al. 1998 INGAP treatment improves glycemic control in streptozotocin diabetic hamsters. Diabetes 47 A253.

Harlan DM, Hengartner H, Huang ML, Kang YH, Abe R, Moreadith RW, Pircher H, Gray GS, Ohashi PS, Freeman GJ et al. 1994 Mice expressing both B7-1 and viral glycoprotein on pancreatic beta cells along with glycoprotein-specific transgenic $\mathrm{T}$ cells develop diabetes due to a breakdown of T-lymphocyte unresponsiveness. PNAS 91 3137-3141.

Hirshberg B, Rother KI \& Harlan DM 2003 Islet transplantation: where do we stand now? Diabetes/Metabolism Research and Reviews 19 175-178.

Jamal AM, Lipsett M, Sladek R, Laganiere S, Hanley S \& Rosenberg L 2005 Morphogenetic plasticity of adult human pancreatic islets of Langerhans. Cell Death and Differentiation 12 702-712.

Kruse F, Rose SD, Swift GH, Hammer RE \& MacDonald RJ 1993 An endocrine-specific element is an integral component of an exocrinespecific pancreatic enhancer. Genes and Development 7 774-786.

Kurlawalla-Martinez C, Stiles B, Wang Y, Devaskar SU, Kahn BB \& Wu H 2005 Insulin hypersensitivity and resistance to streptozotocin-induced diabetes in mice lacking PTEN in adipose tissue. Molecular Cell Biology 25 2498-2510.

Kurup S \& Bhonde RR 2000 Combined effect of nicotinamide and streptozotocin on diabetic status in partially pancreatectomized adult $\mathrm{BALB} / \mathrm{c}$ mice. Hormone and Metabolic Research 32 330-334.

Lu Y, Herrera PL, Guo Y, Sun D, Tang Z, LeRoith D \& Liu JL 2004 Pancreatic-specific inactivation of IGF-I gene causes enlarged pancreatic islets and significant resistance to diabetes. Diabetes 53 3131-3141.

MacDonald RJ \& Swift GH 1998 Analysis of transcriptional regulatory regions in vivo. International Journal of Developmental Biology 42 983-994.

Mathis D, Vence L \& Benoist C 2001 Beta-cell death during progression to diabetes. Nature 414 792-798.

Okamoto H 1999 The Reg gene family and Reg proteins: with special attention to the regeneration of pancreatic beta-cells. Journal of HepatoBiliary-Pancreatic Surgery 6 254-262.

Paris M, Tourrel-Cuzin C, Plachot C \& Ktorza A 2004 Review: pancreatic beta-cell neogenesis revisited. Experimental Diabesity Research 5 111-121.

Prado CL, Pugh-Bernard AE, Elghazi L, Sosa-Pineda B \& Sussel L 2004 Ghrelin cells replace insulin-producing beta cells in two mouse models of pancreas development. PNAS 101 2924-2929.

Rafaeloff R, Qin XF, Barlow SW, Rosenberg L \& Vinik AI 1996 Identification of differentially expressed genes induced in pancreatic islet neogenesis. FEBS Letters 378 219-223.

Rafaeloff R, Pittenger GL, Barlow SW, Qin XF, Yan B, Rosenberg L, Duguid WP \& Vinik AI 1997 Cloning and sequencing of the pancreatic islet neogenesis associated protein (INGAP) gene and its expression in islet neogenesis in hamsters. Journal of Clinical Investigation 99 2100-2109.
Ratner RE \& Feeley D 2005a Double-blind, placebo-controlled trial of Islet Neogenesis Gene Associated Protein (INGAP) in subjects with Type1 Diabetes Mellitus (T1DM). American Diabetes Association Scientific Sessions Abstracts Archive 11-LB.

Ratner RE \& Feeley D $2005 b$ Double-blind, placebo-controlled trial of Islet Neogenesis Gene Associated Protein (INGAP) in subjects with Type 2 Diabetes Mellitus (T2DM). American Diabetes Association Scientific Sessions Abstracts Archive 12-LB.

Rosenberg L 1995 In vivo cell transformation: neogenesis of beta cells from pancreatic ductal cells. Cell Transplantation 4 371-383.

Rosenberg L, Vinik AI, Pittenger GL, Rafaeloff R \& Duguid WP 1996 Isletcell regeneration in the diabetic hamster pancreas with restoration of normoglycaemia can be induced by a local growth factor(s). Diabetologia 39 256-262.

Rosenberg L, Lipsett M, Yoon JW, Prentki M, Wang R, Jun HS, Pittenger GL, Taylor-Fishwick D \& Vinik AI 2004 A pentadecapeptide fragment of islet neogenesis-associated protein increases beta-cell mass and reverses diabetes in C57BL/6J mice. Annals of Surgery 240 875-884.

Slack JM 1995 Developmental biology of the pancreas. Development 121 $1569-1580$.

Song L, Taylor-Fishwick DA \& Park I 2005 Chronological expression of INGAP (islet neogenesis associated protein) and clusterin during pancreas regeneration. Diabetes 54 A650.

Suarez-Pinzon WL, Lakey JR, Brand SJ \& Rabinovitch A 2005 Combination therapy with epidermal growth factor and gastrin induces neogenesis of human islet $\beta$-cells from pancreatic duct cells and an increase in functional $\beta$-cell mass. Journal of Clinical Endocrinology and Metabolism 6 3401-3409.

Swift GH, Kruse F, MacDonald RJ \& Hammer RE 1989 Differential requirements for cell-specific elastase I enhancer domains in transfected cells and transgenic mice. Genes and Development 3 687-696.

Taylor-Fishwick DA, Rittman S, Kendall H, Roy L, Shi W, Cao Y, Pittenger GL \& Vinik AI 2003 Cloning genomic INGAP: a Reg-related family member with distinct transcriptional regulation sites. Biochimica et Biophysica Acta 1638 83-89.

Tuttle RL, Gill NS, Pugh W, Lee JP, Koeberlein B, Furth EE, Polonsky KS, Naji A \& Birnbaum MJ 2001 Regulation of pancreatic beta-cell growth and survival by the serine/threonine protein kinase Akt1/PKBalpha. Nature Medicine 7 1133-1137.

UKPDS Group 1995 UK prospective diabetes study 16. Overview of 6 years' therapy of type II diabetes: a progressive disease. UK Prospective Diabetes Study Group. Diabetes 44 1249-1258.

Vinik A, Rafaeloff R, Pittenger G, Rosenberg L \& Duguid W 1997 Induction of pancreatic islet neogenesis. Hormone and Metabolic Research 29 278-293.

Vinik AI, Rosenberg L, Pittenger GL \& Taylor-Fishwick DA 2004a Stimulation of pancreatic islet neogenesis: a possible treatment for type 1 and type 2 diabetes. Current Opinion Endocrinology Diabetes 11 125-140.

Vinik AI, Taylor-Fishwick DA \& Pittenger GL 2004b Advances in diabetes for the Millenium: toward a cure for diabetes. Medscape General Medicine 6 1-6.

Wilson GL, Hartig PC, Patton NJ \& LeDoux SP 1988 Mechanisms of nitrosourea-induced beta-cell damage. Activation of poly (ADP-ribose) synthetase and cellular distribution. Diabetes 37 213-216.

Yamamoto H, Uchigata Y \& Okamoto H 1981 Streptozotocin and alloxan induce DNA strand breaks and poly(ADP-ribose) synthetase in pancreatic islets. Nature 294 284-286.

Zhu L, Tran T, Rukstalis JM, Sun P, Damsz B \& Konieczny SF 2004 Inhibition of Mist1 homodimer formation induces pancreatic acinarto-ductal metaplasia. Molecular and Cellular Biology 24 2673-2681.

Received 20 April 2006

Received in final form 12 May 2006

Accepted 22 May 2006 